\title{
Assessment of the association of serum progranulin with autophagy in diabetic patients
}

\author{
Nahla S. Hassan', Nievien A. Mahran², Marwa G.A. Hegazy \\ ${ }^{1}$ Biochemistry Department, Faculty of Science, Ain Shams University, Cairo, Egypt \\ ${ }^{2}$ Faculty of Dentistry, Sinai University, Kantra, Egypt
}

\begin{abstract}
Introduction: Progranulin (PGRN) has newly arisen as an important regulatory protein of glucose metabolism and insulin sensitivity. Progranulin expression is interrelated with lysosomal function strongly linked to autophagy pathway. We aimed to evaluate the correlation between PGRN protein and microtubule-associated protein light chain 3B (LC3B) expression level in diabetic patients.

Material and methods: Blood samples of 70 type 2 diabetic Egyptian patients were provided for analysis of concentrations of serum progranulin and interleukin 6 (IL-6) using ELISA, and quantifying expression of LC3B RNA level using qPCR. A group of 20 healthy volunteers were also enrolled.

Results: Serum levels of PGRN and IL-6 as well as LC3B gene expression levels were markedly higher in type 2 diabetic patients. Additionally, our study revealed a cut-off value of $18.14 \mathrm{ng} / \mathrm{mL}$ for progranulin serum level and 3.23 for LC3B expression level, with sensitivities of $83.6 \%$ and $75.4 \%$ and specificities of $83.8 \%$ and $58.3 \%$, respectively. Circulating PGRN levels are positively correlated with body mass index (BMI), glucose concentration, and IL-6.

Conclusion: Our results support the hypothesis that progranulin is introduced as a novel marker of chronic inflammatory response in type 2 diabetes that aggravates insulin resistance via activated autophagy, indicating the importance of this novel adipokine in the regulation of glucose metabolism and as a promising therapeutic target in the treatment of diabetes. (Endokrynol Pol 2020; 71 (1): 51-57)
\end{abstract}

Key words: diabetes; progranulin; autophagy; microtubule-associated proteins light chain 3B; interleukin 6

\section{Introduction}

Progranulin (PGRN) is a $68-88 \mathrm{kDa}$ cysteine-rich secreted protein, also known as granulin-epithelin precursor, proepithelin, or PC-cell-derived growth factor [1, 2]. It is encoded by GRN (PGRN gene) and expressed in many cell types, including epithelial cells, immune cells, neurons, and adipocytes. Progranulin is secreted in an intact form and can be cleaved into granulins by proteases [3]. Granulins are small proteins of approximately $6 \mathrm{kDa}$ characterised by a conserved motif of 12 cysteines, and they play a role in the extracellular regulation of cell function and growth [2].

Progranulin, as an autocrine growth factor, has recently been found to play a role in a variety of physiological and pathological processes, including inflammation, and glucose and lipid metabolism [4]. Recent studies found that administration of progranulin caused glucose intolerance and insulin insensitivity through the triggering of autophagy in the adipose tissue of mice [5], suggesting that progranulin could be a critical adipokine regulating glucose and lipid metabolism.
Progranulin is emerging as an important regulatory adipokine of glucose metabolism and insulin sensitivity. Individuals with visceral obesity and type 2 diabetes (T2D) were shown to have increased PGRN serum levels [6]. Additionally, circulating PGRN levels are positively correlated with body mass index (BMI), fat mass, fasting glucose, insulin levels, and insulin resistance, the hallmark of T2D [6, 7].

Moreover, it has been found that PGRN plays an important role in inflammation as anti-inflammatory protein affecting the tumour necrosis factor receptor (TNFR) signalling. Additionally, TNFR have been identified as receptors of PGRN. Progranulin binds and antagonises both TNFR1 and TNFR2, inhibiting TNF $\alpha$ signalling pathway in a dose-dependent manner. The $\mathrm{TNF} \alpha$ signalling pathway is a major mediator of inflammation, and it is involved in different human diseases including diabetes and rheumatoid arthritis [8].

Several studies have been performed in order to elucidate the association between PGRN and metabolic diseases. Elevated levels of PGRN were found in the white adipose tissue of a well characterised mouse model of 
obesity. The administration of murine recombinant PGRN to wild-type mice induced an increase of serum insulin level, increased fat mass, insulin resistance, and elevated levels of interleukin 6 (IL-6), which is strongly involved in the development of insulin resistance [9]. Therefore, PGRN mediates insulin resistance in vivo, inducing IL-6 expression in adipose tissue [10].

Likewise, it has been found that short-term treatment with recombinant PGRN induces insulin resistance both in murine liver and hepatocytes, and this was associated with defective autophagy [11]. The relationship between autophagy and PGRN was attributed to the involvement of a variety of adipocytokines, including IL-6 and TNF $\alpha$ [12]. Interestingly, PGRN-induced insulin resistance and defective autophagy in liver was found to be reverted by the administration of a TNFR blocking peptide, thus indicating that PGRN mediates insulin resistance and impaired autophagy via TNFR signalling in the liver [11].

Furthermore, experimental studies reported that PGRN increases autophagic activity and triggers endoplasmic reticulum (ER) stress in cultured human adipocytes, having an impact on insulin signalling [9].

Autophagy is the major mechanism involved in the degradation and recycling of intracellular components, and its alterations have been proposed to cause beta cell dysfunction [13]. However, autophagy may be enhanced under a variety of atrophic conditions, as shown by the expression of several proteins involved in lysosomal degradation, including LC3 [14]. Microtubule-associated protein 1A/1B light chain $3 \mathrm{~B}$ (hereafter referred to as LC3) is a protein that in humans is encoded by the MAP1LC3B gene, and it is a member of the highly conserved ATG8 protein family. LC3 is a central protein in the autophagy pathway, where it functions in autophagy substrate selection and autophagosome biogenesis. LC3 is the most widely used marker of autophagosomes [15].

To the best of our knowledge, we were the first to investigate the correlation between PGRN and autophagy with reference to inflammatory response in diabetic patients.

\section{Material and methods}

\section{Subjects}

This cross-sectional study was approved by the Ethical Committee of Al-Azhar University and was conducted in accordance with the Helsinki Declaration. All subjects signed written, informed consent, and this consent procedure was approved by the Ethics Boards of Al-Hussein hospital.

The analysis was performed on 70 Egyptian patients who were diagnosed with diabetes mellitus type 2 and attended the Intensive Care Unit (ICU) of Al-Hussein hospital, Al-Azhar University, and 20 healthy normal volunteers age- and sex-matched with the patient group.
The participant inclusion criteria included being in the age range $35-70$ years, having DM and hypertension for a minimum of five years, systolic blood pressure $>140 \mathrm{~mm} \mathrm{Hg}$ or diastolic blood pressure $>90 \mathrm{~mm} \mathrm{Hg}$ under antihypertensive treatment, and the absence of medication that might interfere with urinary albumin excretion. Patients with renal tract pathological conditions, cardiovascular disease, non-diabetic kidney diseases, malignancy diagnosis, obstructive uropathy, hepatitis, HIV, who had begun dialysis, or had received a renal transplant were excluded from the study.

\section{Samples}

A total of 70 blood samples were collected from T2DM patients (41 males and 29 female) in addition to 20 samples from healthy persons as control samples (12 males and eight females). Sera were collected following a standardised protocol at least 6-8 $\mathrm{h}$ after the last meal, from samples in sterile falcon tubes, and prepared for RNA isolation and the indicated biochemical analysis then stored within $15 \mathrm{~min}$ at $-80^{\circ} \mathrm{C}$.

\section{Laboratory and biochemical parameters}

Samples of all participants were labelled with a unique identifier to protect subject confidentiality. Blood sugar was measured using the glucose oxidase method, serum glycosylated haemoglobin $\left(\mathrm{HbA}_{1 \mathrm{c}}\right)$ was tested on an Olympus AU640 (Japan), and cholesterol, highdensity lipoprotein-cholesterol (HDL-C), as well as low-density lipoprotein-cholesterol (LDL-C) were detected on a Hitachi 7180 analyser (Japan) with commercial reagents.

Body mass index (BMI) was determined as weight (in kilograms) divided by height (in metres) squared. Systolic and diastolic blood pressure were measured from the subjects' right hand using a standard mercury manometer, with subjects in a sitting position.

\section{Enzyme-linked immunosorbent assay (ELISA)}

Concentrations of serum PGRN were analysed using a commercially available ELISA kit (Wuhan Fine Biotech Co., Ltd, China) and that of serum IL-6 using Quantikine (R\&D Systems, Inc., USA) according to the manufacturer's instructions.

\section{Quantitative real-time PCR}

Total RNA for LC3B and glyceraldehyde 3-phosphate dehydrogenase (GAPDH) was isolated using TriZol (Invetrogen) and chloroform then dissolved in RNase free water. The RNA concentration and purity were confirmed using an Ultraspec 1000, UV/visible spectrophotometer Amersham Pharmacia Biotech, Cambridge, England) and NanoDrop 2000 (Thermo Scientific, USA). $100 \mathrm{ng}$ of total RNA was reverse transcribed into single-stranded complementary DNA by using a miScript Reverse Transcription Kit (Qiagen, MD) following the manufacturer's protocol. The synthesised complementary DNA was used for quantitative polymerase chain reaction using the qPCR tubes then run on a StepOnePlus ${ }^{\mathrm{TM}}$ System (Applied Biosystems, Inc., Foster, CA) in the presence of QuantiTect SYBR Green PCR Kit (Qiagen, MD), and the results were computerised. The following gene-specific primers were used: LC3Bforward-5'- ATACBCCTCTCAGGAGACTTT-3', LC3B-reverse-5'CCAAATGAGAACTCTGGAACG-3', and GAPDH-forward, 5'-GTC TCC TCT GAC TTC AAC AGC G-3' and GAPDH-reverse, 5'-ACC ACC CTG TTG CTG TAG CCA A-3'.

Target sequences were amplified at $95^{\circ} \mathrm{C}$ for 15 minutes, followed by 40 cycles at $94^{\circ} \mathrm{C}$ for 15 seconds and $55^{\circ} \mathrm{C}$ for 30 seconds, then for 30 seconds at $70^{\circ} \mathrm{C}$. GAPDH was used as an endogenous normalisation control. All assays were performed in triplicate. The fold change in messenger RNA expression was determined in DM patients compared to controls according to the $2^{-\Delta \Delta \mathrm{Ct}}$ method, where $\Delta \mathrm{CT}$ $=\mathrm{CT}$ target gene $-\mathrm{CT}$ reference gene and $\Delta \Delta \mathrm{CT}=\Delta \mathrm{CT}$ (sample 2) $-\Delta \mathrm{CT}$ (sample 1 ), and where sample 1 is the control sample and sample 2 is the experimental sample [16]. 


\section{Statistical analysis}

Statistical analysis was performed using SPSS version 21.0 (SPSS, Chicago, IL, USA). Data are presented as mean \pm standard deviation. $\mathrm{P}<0.05$ was considered statistically significant. Differences in the measured expression of MAP1LC3B mRNA between healthy individuals and diabetic patient groups were analysed by oneway analysis of variance (ANOVA). Correlations were evaluated by Spearman correlation coefficient. The diagnostic accuracy of the progranulin, IL-6, and LC3B gene for DM were evaluated by receiver operating characteristic (ROC) analysis.

\section{Results}

The baseline demographic and biochemical characteristics of the study population are summarised in Table 1. Progranulin and IL-6 showed a significant increase in the diabetic patients compared to normal subjects. The expression level of LC3B mRNA was measured, and its level was significantly increased in the diabetic patients when compared to the control subjects (Fig. 1).

The receiver operating characteristic (ROC) curve was designed to distinguish diabetic patients from the control group (Fig. 2), and the results revealed that the best cut-off values of progranulin, IL-6, and LC3 are 18.14, 1.33 , and 3.23 , respectively, with certain sensitivities and specificities (Tab. 2). Combined sensitivities and specificities of PGRN, IL-6, and LC3 are represented in Table 3.

Regarding correlations, progranulin levels were positively correlated with BMI, glucose concentration, and IL-6. LC3 expression levels were negatively correlated with glucose concentration, LDL, CHL, and systolic pressure, and positively with diastolic pressure. Also,

Table 1. Clinical characteristics of the participants among the different groups in the study

\begin{tabular}{|c|c|c|c|c|c|c|c|c|}
\hline & \multicolumn{6}{|c|}{ Groups } & \multirow{3}{*}{ p } & \multirow{3}{*}{$F^{(a)}$} \\
\hline & \multicolumn{3}{|c|}{ Diabetic patients } & \multicolumn{3}{|c|}{ Healthy volunteers } & & \\
\hline & Mean & Median & $\pm S D$ & Mean & Median & $\pm S D$ & & \\
\hline Age [years] & 54.75 & 55.00 & 9.24 & 54.25 & 54.50 & 5.69 & 0.856 & 0.33 \\
\hline BMI $\left[\mathrm{kg} / \mathrm{m}^{2}\right]$ & 34.99 & 35 & 3.42 & 28.67 & 29.00 & 2.39 & $0.002^{*}$ & 10.265 \\
\hline $\mathrm{HbA}_{1 \mathrm{c}}(\%)$ & 5.80 & 5.50 & 0.91 & 4.87 & 5.000 & 0.74 & $0.001^{*}$ & 11.215 \\
\hline Glucose [mg/dl] & 280.70 & 262.00 & 114.35 & 111.17 & 111.50 & 5.32 & $0.000^{*}$ & 26.072 \\
\hline SBP [mm Hg] & 123.60 & 125.0 & 9.88 & 114.17 & 120.00 & 9.73 & $0.003^{*}$ & 9.197 \\
\hline $\mathrm{DBP}[\mathrm{mm} \mathrm{Hg}]$ & 80.73 & 80.00 & 5.76 & 79.16 & 80.00 & 9.96 & 0.570 & .453 \\
\hline $\mathrm{HDL}$ [mmol/L] & 33.72 & 31.00 & 8.12 & 33.67 & 31.50 & 8.80 & 0.983 & .000 \\
\hline LDL [mmol/L] & 127.65 & 118.00 & 30.15 & 119.16 & 110.00 & 23.25 & 0.360 & 0.848 \\
\hline Cholesterol [mmol/L] & 207.24 & 200.00 & 33.16 & 204.16 & 200.00 & 29.37 & 0.766 & 0.089 \\
\hline Duration [years] & 11.64 & 12.00 & 4.66 & 00 & 00 & 00 & $0.000^{*}$ & 73.961 \\
\hline
\end{tabular}

$\mathrm{BMI}$ — body mass index; $\mathrm{HbA}_{1 \mathrm{c}}$ — glycosylated haemoglobin; SBP — systolic blood pressure; DBP — diastolic blood pressure; HDL — high-density lipoprotein; LDL — low-density lipoprotein; SD — standard deviation; ${ }^{a}$ one-way ANOVA test; ${ }^{*} p<0.05$ : significantly different

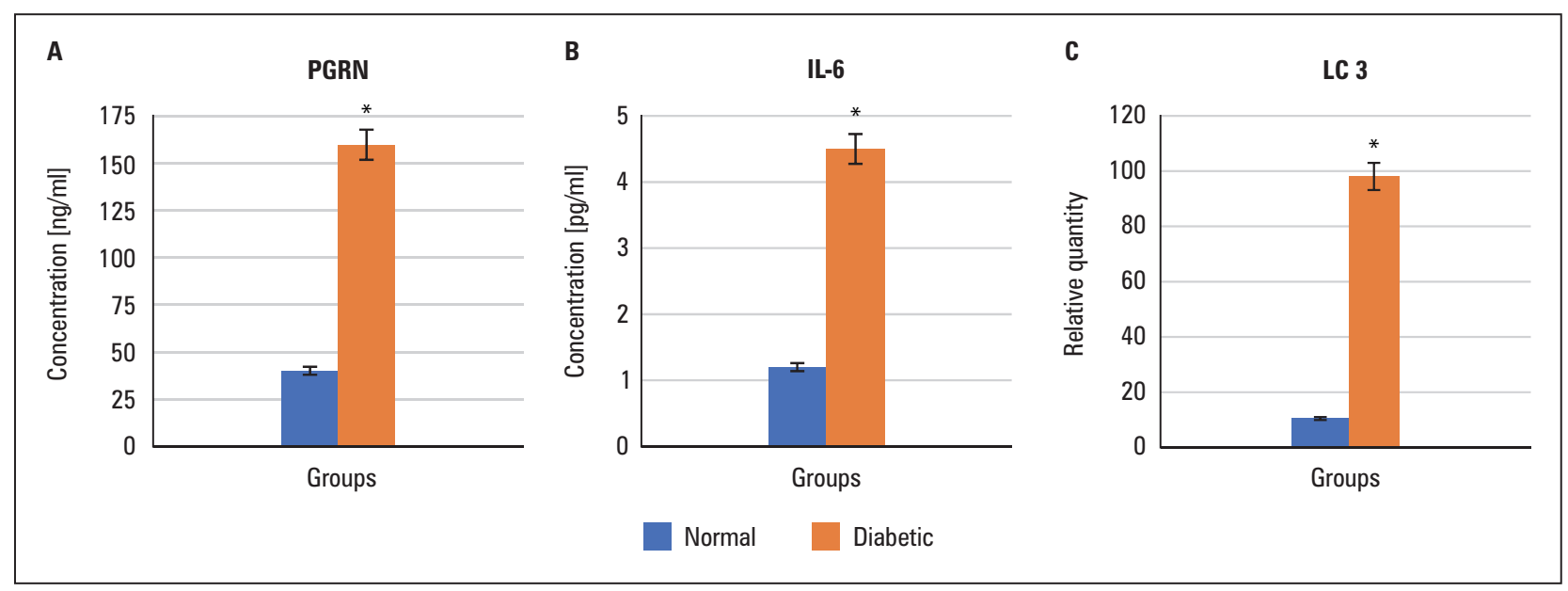

Figure 1. Differential expression of light chain (LC3), protein level of progranulin (PGRN) and interleukin 6 (IL-6) among different groups $(n=90)$. Values expressed as mean $\pm S E .{ }^{*} p<0.05$ is significant when compared to controls 


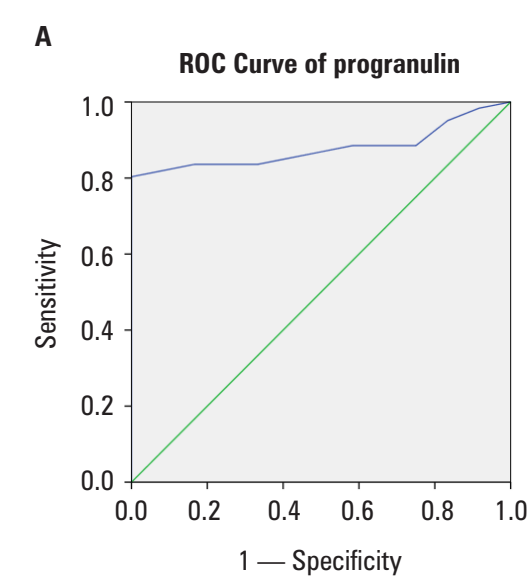

B

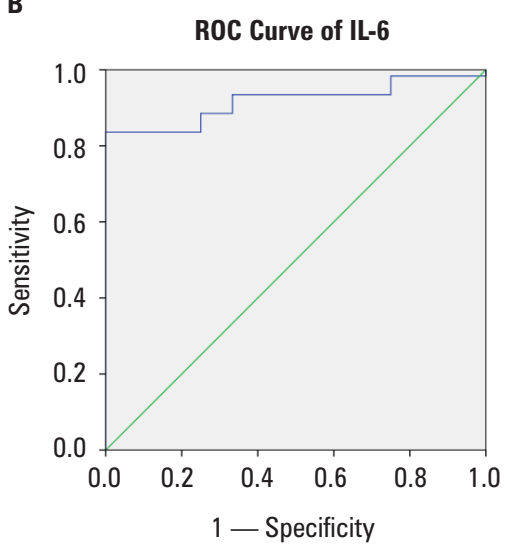

C

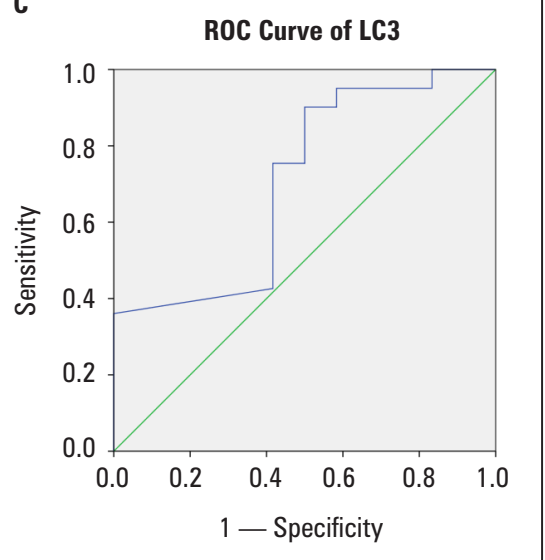

Figure 2. Receiver operating characteristic (ROC) curves of (A) progranulin, (B) interleukin 6 (IL-6), (C) light chain 3B (LC3)

Table 2. Area under curve (AUC), cut-off value, and performance characteristics of progranulin (PGRN), interleukin 6 (IL-6), and light chain $3 B$ (LC3) to discriminate diabetic patients from the control group

\begin{tabular}{lcccc}
\hline Parameter & AUC & Cut-off value & Sensitivity & Specificity \\
\hline PGRN & 0.878 & 18.141 & $83.6 \%$ & $83.3 \%$ \\
\hline IL-6 & 0.918 & 1.33 & $88.5 \%$ & $75.8 \%$ \\
\hline LC3 & 0.706 & 3.233 & $75.4 \%$ & $58.3 \%$ \\
\hline
\end{tabular}

Table 3. Combined sensitivity and specificity of progranulin (PGRN), interleukin 6 (IL-6), and light chain 3B (LC3)

\begin{tabular}{lcc}
\hline $\begin{array}{l}\text { Combined } \\
\text { parameters }\end{array}$ & $\begin{array}{l}\text { Combined } \\
\text { Sensitivity }\end{array}$ & $\begin{array}{l}\text { Combined } \\
\text { Specificity }\end{array}$ \\
\hline PGRN + IL-6 & $96.7 \%$ & $83.3 \%$ \\
\hline PGRN + LC3 & $96.7 \%$ & $83.3 \%$ \\
\hline IL-6+ LC3 & $100 \%$ & $75.0 \%$ \\
\hline PGRN + IL-6 + LC3 & $100 \%$ & $58.3 \%$ \\
\hline
\end{tabular}

levels of IL-6 were positively correlated with glucose concentration and systolic pressure (Tab. 4).

\section{Discussion}

Progranulin is a protein with growth factor-like properties regulating several biological functions. Interestingly, PGRN has been found to be strongly involved in metabolism [17].

New markers have been studied in the pathogenesis of diabetes, involving many adipokines [18, 19], such as PGRN [7]. There is evidence that PGRN levels are increased in T2DM when compared to non-diabetic subjects. PGRN is closely related to glucose metabolism. Furthermore, there is a positive correlation between PGRN and plasma glucose $A_{1 c}[6,20]$. Elevated PGRN concentrations are also observed in subjects with impaired glucose tolerance, revealing its role in prediabetic states [20].

In agreement with these findings, the present study showed significantly elevated PGRN protein concentration in the diabetic group when compared to the controls; furthermore, $\mathrm{HbA}_{1 \mathrm{c}}$ and $\mathrm{BMI}$ were significantly increased in the diabetic group.

Obesity and visceral fat are probably the main risk factors for T2D [9] and are involved in its pathophysiology as well as inflammation and insulin resistance [21]. Moreover, a study evaluating T2DM patients reported that obese subjects present higher levels of PGRN [13]. Taking in consideration the fact that $\mathrm{BMI}$ is a simple index of weight-for-height that is commonly used to classify overweight and obesity in adults, this study agreed with our finding revealing a significant difference of BMI between diabetic and control groups with significant positive correlation with PGRN.

Further studies in the last decade have shown that inflammation is a key process in the development of diabetes mellitus [22]. The association of PGRN with T2DM is mainly explained by its role in adipose tissue and insulin resistance. Progranulin promotes IL-6 expression, impairing insulin signalling [10]. Moreover, it is a chemoattractant protein that recruits monocytes 
Table 4. Correlation between progranulin (PGRN), light chain 3B LC3 (LC3), and interleukin 6 (IL-6) and clinical parameters among groups of study

\begin{tabular}{|c|c|c|c|c|}
\hline Parameter & & PGRN & LC3 & IL-6 \\
\hline \multirow{2}{*}{ Glucose } & Correlation coefficient (r) & .231 & -.308 & .424 \\
\hline & Sig. (2-tailed) $(P)$ & $.049 *$ & $.008 *$ & $.000 *$ \\
\hline \multirow{2}{*}{$\mathrm{HbA}_{1 \mathrm{c}}$} & Correlation coefficient ( $r$ ) & .090 & -.100 & -.098 \\
\hline & Sig. (2-tailed) $(P)$ & .451 & .400 & .411 \\
\hline \multirow{2}{*}{ BMI } & Correlation coefficient (r) & .351 & .135 & .169 \\
\hline & Sig. (2-tailed) $(P)$ & $.002 *$ & .257 & .152 \\
\hline \multirow{2}{*}{ SBP } & Correlation coefficient (r) & .108 & -.353 & .382 \\
\hline & Sig. (2-tailed) $(P)$ & .362 & $.002^{*}$ & $.001^{*}$ \\
\hline \multirow{2}{*}{ DBP } & Correlation coefficient (r) & .075 & .257 & .055 \\
\hline & Sig. (2-tailed) $(P)$ & .527 & $.028 *$ & .643 \\
\hline \multirow{2}{*}{ HDL } & Correlation coefficient (r) & -.159 & -.018 & -.013 \\
\hline & Sig. (2-tailed) $(P)$ & .179 & .878 & .916 \\
\hline \multirow{2}{*}{ LDL } & Correlation coefficient (r) & .165 & -.305 & .064 \\
\hline & Sig. (2-tailed) $(P)$ & .164 & $.009^{*}$ & .593 \\
\hline \multirow{2}{*}{ CHL } & Correlation coefficient (r) & .087 & -.313 & .054 \\
\hline & Sig. (2-tailed) $(P)$ & .467 & $.007^{*}$ & .649 \\
\hline \multirow{2}{*}{ Duration } & Correlation coefficient (r) & .362 & -.042 & .394 \\
\hline & Sig. (2-tailed) $(P)$ & $.002^{*}$ & .725 & $.001 *$ \\
\hline \multirow{2}{*}{ Progranulin } & Correlation coefficient (r) & 1.000 & .020 & .397 \\
\hline & Sig. (2-tailed) $(P)$ & - & .865 & $.000^{*}$ \\
\hline \multirow{2}{*}{ LC3 } & Correlation coefficient (r) & .020 & 1.000 & -.122 \\
\hline & Sig. (2-tailed) $(P)$ & .865 & - & .302 \\
\hline \multirow{2}{*}{ IL-6 } & Correlation coefficient (r) & .397 & -.122 & 1.000 \\
\hline & Sig. (2-tailed) $(P)$ & $.000^{*}$ & .302 & - \\
\hline
\end{tabular}

$\mathrm{BMI}$ — body mass index; $\mathrm{HbA}_{1 \mathrm{c}}$ — glycosylated haemoglobin; SBP — systolic blood pressure; DBP — diastolic blood pressure; HDL — high-density lipoprotein; LDL — low-density lipoprotein; Spearman's correlation $p$ : not significant $(>0.05),{ }^{*} p<0.05$ : significant

into adipose tissue, promoting inflammatory response with increased cytokines levels [6].

The physiological function of PGRN is complex, with the full-length form of the protein having trophic and anti-inflammatory activity, whereas proteolytic cleavage generates granulin peptides that promote inflammatory activity [23]. During the inflammatory process, progranulin is digested into smaller peptides, called granulins, which are proinflammatory and neutralise the anti-inflammatory effect of intact progranulin [24].

In the current study PGRN concentrations and the inflammatory marker IL-6 are markedly elevated in the sera of T2DM. Furthermore, serum PGRN levels had remarkable positive correlations with IL-6. Kloeting et al. [25] present evidence that progranulin induces proinflammatory IL-6. Therefore, it is speculated that serum PGRN could stimulate the adipocytes to release more IL-6.

Experimental studies reported that PGRN promotes IL-6 expression in adipose cells, and its elevation en- hances cytokine signaling-3 (SOCS3) expression via activation of JAK-STAT signalling. This mechanism can inhibit tyrosine phosphorylation of insulin receptor substrate-1 (IRS-1), leading to insulin resistance [10].

Furthermore, Guo et al. [26] explored the mechanism of progranulin action and revealed that progranulin treatment activated oxidative stress and endoplasmic reticulum (ER) stress, elevated autophagy, and induced insulin insensitivity in adipocytes and adipose tissue of mice.

Autophagy is a highly conserved pathway. Impairment of autophagy is implicated in the pathogenesis of diabetes. Furthermore, autophagy has been closely linked to inflammation in part by regulation of adipokine production. Experimental study showed that mice with a conditional deletion of autophagy gene (Atg7) in the intestinal epithelium showed enhanced mRNA expression of interleukin $1 \beta$ (IL-1 $\beta$ ) [27]. Additional studies in vivo demonstrated that obesity-induced endoplasmic reticulum stress causes chronic inflammation 
in adipose tissue, as shown by up-regulation of tumour necrosis factor alpha (TNF $\alpha)$, IL-1 $\beta$, and IL-6 [28]. These observations raised the possibility that PGRN might be a promising new link among obesity, autophagy and insulin resistance (i.e. diabetes).

It was revealed that administration of PGRN attenuated insulin signalling and triggered autophagy in in vivo and in vitro studies, suggesting a causative role of tumour necrosis factor receptor 1 (TNFR1) in PGRN-induced impaired insulin sensitivity, implicating that decreasing PGRN level, by influencing its turnover or production, is consequently a promising therapeutic approach applied to metabolic disorders [5].

Linnemann et al. [29] reported that IL-6 robustly activates signal transducer and activator of transcription 3 (STAT3), a transcription factor that is involved in autophagy. The authors also reported that IL-6 stimulates LC3 conversion and autophagosome formation in cultured pancreatic $\beta$ cells. In the same study, both mRNA and protein expression of ATG7 (the enzyme responsible for the fatty acid conjugation that converts LC3-I to LC3-II) were stimulated by IL-6. IL-6-mediated regulation of autophagy occurs through multiple complementary mechanisms involving both repression of mammalian target of rapamycin complex 1 (mTORC1) and stimulation of mammalian target of rapamycin complex 2 (mTORC2).

Direct stimulation of autophagy is a novel mechanism for IL-6-mediated protection of pancreatic $\beta$ cells from stress-induced apoptosis [29]. This is consistent with previous observations that exercise (which stimulates IL-6) activates autophagy in muscle cells and is critical for cellular homeostasis [30]. Because the IL-6 receptor and its downstream signalling target are both down-regulated in human islets in type 2 diabetes [29], IL-6-mediated autophagy stimulation appears to be impaired in type 2 diabetes. It is hypothesised that the inability of the diabetic islet to respond to increased circulating IL- 6 in diabetes may contribute to $\beta$-cell dysfunction and death.

Indeed, the expression level of LC3II is highly correlated with the number of autophagosomes [15]. Paula-Gomes et al. [31] reported that LC3 mRNA and, consequently, LC3II protein levels were enhanced in the heart tissue of diabetic animals and in fasted cardiomyocytes, suggesting that the autophagic flux is increased, which concurred with our findings. In the present study, the expression level of LC3B mRNA indicated a significant elevation in the diabetic group compared to the normal group.

On the other hand, insulin treatment of the patient in another study was suggested to be responsible for the reduction in the level of LC3B. Also, Su et al. [32] reported that the expressions of LC3, ATG5, BECN1,
Cathepsin B, and FOXO3A proteins in ovaries from insulin-treated mice were significantly reduced compared to those from control mice.

In addition, in the present study the ROC curve showed that progranulin had higher specificity than IL-6 and LC 3 but lower sensitivity than IL-6 and higher sensitivity than LC3. The combined use of the three parameters increased the sensitivity, reaching $100 \%$.

Although the potential role of progranulin in activating autophagy and inducing insulin resistance has been identified, the intracellular events responsible for progranulin-mediated effects in autophagy and diabetes remain not fully understood.

\section{Conclusion}

In conclusion, this body of evidence, combined with our findings, strongly suggests that PGRN is a novel marker that plays role in inflammatory response in type 2 diabetic patients via activated autophagy. Moreover, this novel adipokine, which is involved in regulation of glucose metabolism, could be a promising therapeutic target in the treatment of diabetes. Additionally, LC3 has great clinical value as a promising biomarker in diabetic assessment.

\section{Ethical approval and consent to participate}

This study was approved by the Ethical Committee of Al-Azhar University and was conducted in accordance with the Helsinki Declaration.

\section{Consent for publication}

All subjects signed written, informed consent, and this consent procedure was approved by the Ethics Boards of Al-Hussein hospital.

\section{Availability of data and materials}

The datasets generated and/or analysed during the current study are not publicly available due to patients' privacy and ethical restrictions but are available from the corresponding author on reasonable request.

\section{Competing interests}

The authors declare that they have no competing interests

\section{Funding}

This study did not receive any funding from specific agencies in the public, commercial, or not-for-profit sectors.

\section{Authors' contributions}

NSH and MGAH conceived of the presented idea, NAM collected samples, NSH, MGAH, and NAM analysed 
and interpreted the patient data, NSH and MGAH carried out the practical experiments, NSH and MGAH drafted the manuscript, and all authors read and approved the final manuscript.

\section{Acknowledgements}

We would like to express our gratitude to the patients, who are the backbone of this study, for their cooperation and for sharing their pearls of wisdom with us during this study.

\section{References}

1. He Z, Bateman A. Progranulin (granulin-epithelin precursor, PC-cell-derived growth factor, acrogranin) mediates tissue repair and tumorigenesis. J Mol Med (Berl). 2003; 81(10): 600-612, doi: 10.1007/s00109-003-0474-3, indexed in Pubmed: 12928786.

2. Zhou J, Gao G, Crabb JW, et al. Purification of an autocrine growth factor homologous with mouse epithelin precursor from a highly tumorigenic cell line. J Biol Chem. 1993; 268(15): 10863-10869, indexed in Pubmed: 8496151.

3. Nguyen AD, Nguyen TA, Martens LH, et al. Progranulin: at the interface of neurodegenerative and metabolic diseases. Trends Endocrinol Metab. 2013; 24(12): 597-606, doi: 10.1016/j.tem.2013.08.003, indexed in Pubmed: 24035620.

4. Kessenbrock K, Fröhlich L, Sixt M, et al. Proteinase 3 and neutrophil elastase enhance inflammation in mice by inactivating antiinflammatory progranulin. J Clin Invest. 2008; 118(7): 2438-2447, doi: 10.1172/JCI34694, indexed in Pubmed: 18568075

5. Zhou Bo, Li H, Liu J, et al. Progranulin induces adipose insulin resistance and autophagic imbalance via TNFR1 in mice. J Mol Endocrinol. 2015 55(3): 231-243, doi: 10.1530/JME-15-0075, indexed in Pubmed: 26373796.

6. Youn BS, Bang SI, Klöting N, et al. Serum progranulin concentrations may be associated with macrophage infiltration into omental adipose tissue. Diabetes. 2009; 58(3): 627-636, doi: 10.2337/db08-1147, indexed in Pubmed: 19056610.

7. Qu H, Deng H, Hu Z. Plasma progranulin concentrations are increased in patients with type 2 diabetes and obesity and correlated with insulin resistance. Mediators Inflamm. 2013; 2013: 360190, doi: 10.1155/2013/360190, indexed in Pubmed: 23476101.

8. Tang W, Lu Yi, Tian QY, et al. The growth factor progranulin binds to TNF receptors and is therapeutic against inflammatory arthritis in mice. Science. 2011; 332(6028): 478-484, doi: 10.1126/science.1199214, indexed in Pubmed: 21393509.

9. Langenberg C, Sharp SJ, Schulze MB, et al. InterAct Consortium Long-term risk of incident type 2 diabetes and measures of overall and regional obesity: the EPIC-InterAct case-cohort study. PLoS Med. 2012; 9(6): e1001230, doi: 10.1371/journal.pmed.1001230, indexed in Pubmed: 22679397.

10. Matsubara T, Mita A, Minami K, et al. PGRN is a key adipokine mediating high fat diet-induced insulin resistance and obesity through IL-6 in adipose tissue. Cell Metab. 2012; 15(1): 38-50, doi: 10.1016/j.cmet.2011.12.002, indexed in Pubmed: 22225875.

11. Liu J, Li H, Zhou Bo, et al. PGRN induces impaired insulin sensitivity and defective autophagy in hepatic insulin resistance. Mol Endocrinol. 2015; 29(4): 528-541, doi: 10.1210/me.2014-1266, indexed in Pubmed: 25664864.

12. Jansen HJ, van Essen P, Koenen T, et al. Autophagy activity is up-regulated in adipose tissue of obese individuals and modulates proinflammatory cytokine expression. Endocrinology. 2012; 153(12): 5866-5874, doi: 10.1210/en.2012-1625, indexed in Pubmed: 23117929.

13. Bugliani M, Mossuto S, Grano F, et al. Modulation of Autophagy Influences the Function and Survival of Human Pancreatic Beta Cells Under Endoplasmic Reticulum Stress Conditions and in Type 2 Diabetes. Front
Endocrinol (Lausanne). 2019; 10: 52, doi: 10.3389/fendo.2019.00052, indexed in Pubmed: 30863363.

14. Lum JJ, Bauer DE, Kong M, et al. Growth factor regulation of autophagy and cell survival in the absence of apoptosis. Cell. 2005; 120(2): 237-248, doi: 10.1016/j.cell.2004.11.046, indexed in Pubmed: 15680329.

15. Kabeya Y, Mizushima N, Ueno T, et al. LC3, a mammalian homologue of yeast Apg8p, is localized in autophagosome membranes after processing. EMBO J. 2000; 19(21): 5720-5728, doi: 10.1093/emboj/19.21.5720, indexed in Pubmed: 11060023

16. Schmittgen TD, Livak KJ. Analyzing real-time PCR data by the comparative C(T) method. Nat Protoc. 2008; 3(6): 1101-1108, doi: 10.1038/nprot.2008.73, indexed in Pubmed: 18546601

17. Li H, Zhou Bo, $\mathrm{Xu} \mathrm{L}$, et al. Circulating PGRN is significantly associated with systemic insulin sensitivity and autophagic activity in metabolic syndrome. Endocrinology. 2014; 155(9): 3493-3507, doi: 10.1210/en.2014-1058, indexed in Pubmed: 24971611.

18. Dunmore SJ, Brown JEP. The role of adipokines in -cell failure of type 2 diabetes. J Endocrinol. 2013; 216(1): T37-T45, doi: 10.1530/JOE-12-0278, indexed in Pubmed: 22991412

19. Bergmann K, Sypniewska G. Diabetes as a complication of adipose tissue dysfunction. Is there a role for potential new biomarkers? Clin Chem Lab Med. 2013; 51(1): 177-185, doi: 10.1515/cclm-2012-0490, indexed in Pubmed: 23241684.

20. Tönjes A, Fasshauer M, Kratzsch J, et al. Adipokine pattern in subjects with impaired fasting glucose and impaired glucose tolerance in comparison to normal glucose tolerance and diabetes. PLoS One. 2010; 5(11): e13911, doi: 10.1371/journal.pone.0013911, indexed in Pubmed: 21085476

21. Waki H, Tontonoz P. Endocrine functions of adipose tissue. Annu Rev Pathol. 2007; 2: 31-56, doi: 10.1146/annurev.pathol.2.010506.091859, indexed in Pubmed: 18039092.

22. Xu L, Zhou Bo, Li H, et al. Serum Levels of Progranulin Are Closely Associated with Microvascular Complication in Type 2 Diabetes. Dis Markers. 2015; 2015: 357279, doi: 10.1155/2015/357279, indexed in Pubmed: 26106251.

23. Eriksen JL, Mackenzie IRA. Progranulin: normal function and role in neurodegeneration. J Neurochem. 2008; 104(2): 287-297, doi: 10.1111/j. 1471-4159.2007.04968.x, indexed in Pubmed: 17953663

24. Liu CJ, Bosch X. Progranulin: a growth factor, a novel TNFR ligand and a drug target. Pharmacol Ther. 2012; 133(1): 124-132, doi: 10.1016/j. pharmthera.2011.10.003, indexed in Pubmed: 22008260.

25. Klöting N, Fasshauer M, Dietrich A, et al. Insulin-sensitive obesity. Am Physiol Endocrinol Metab. 2010; 299(3): E506-E515, doi: 10.1152/ajpendo.00586.2009, indexed in Pubmed: 20570822

26. Guo Q, Xu L, Li H, et al. Progranulin causes adipose insulin resistance via increased autophagy resulting from activated oxidative stress and endoplasmic reticulum stress. Lipids Health Dis. 2017; 16(1): 25, doi: 10.1186/s12944-017-0425-6, indexed in Pubmed: 28143512.

27. Crişan TO, Plantinga TS, van de Veerdonk FL, et al. Inflammasome-independent modulation of cytokine response by autophagy in human cells. PLoS One. 2011; 6(4): e18666, doi: 10.1371/journal.pone.0018666, indexed in Pubmed: 21490934

28. Kawasaki N, Asada R, Saito A, et al. Obesity-induced endoplasmic reticulum stress causes chronic inflammation in adipose tissue. Sci Rep. 2012; 2: 799, doi: 10.1038/srep00799, indexed in Pubmed: 23150771.

29. Linnemann AK, Blumer J, Marasco MR, et al. Interleukin 6 protects pancreatic cells from apoptosis by stimulation of autophagy. FASEB J. 2017; 31(9): 4140-4152, doi: 10.1096/fj.201700061RR, indexed in Pubmed: 28592636.

30. Grumati P, Coletto L, Schiavinato A, et al. Physical exercise stimulates autophagy in normal skeletal muscles but is detrimental for collagen VI-deficient muscles. Autophagy. 2011; 7(12): 1415-1423, doi: 10.4161/auto.7.12.17877, indexed in Pubmed: 22024752.

31. Paula-Gomes S, Gonçalves DAP, Baviera AM, et al. Insulin suppresses atrophy- and autophagy-related genes in heart tissue and cardiomyocytes through AKT/FOXO signaling. Horm Metab Res. 2013; 45(12): 849-855, doi: 10.1055/s-0033-1347209, indexed in Pubmed: 23757118.

32. Su Y, Wu J, He J, et al. High insulin impaired ovarian function in early pregnant mice and the role of autophagy in this process. Endocr J. 2017; 64(6): 613-621, doi: 10.1507/endocrj.EJ16-0494, indexed in Pubmed: 28420820. 